\title{
Serotonin transporter genotype linked to adolescent substance use treatment outcome through externalizing behavior
}

\author{
Tammy Chung ${ }^{1}$, Jack R. Cornelius ${ }^{1}$, Christopher S. Martin ${ }^{1}$, Robert Ferrell ${ }^{2}$, Stephen A. Maisto ${ }^{3}$ and \\ Duncan B. Clark ${ }^{1}$
}

${ }^{1}$ Western Psychiatric Institute and Clinic, University of Pittsburgh Medical Center, Pittsburgh, PA, USA

${ }^{2}$ Department of Human Genetics, University of Pittsburgh, Pittsburgh, PA, USA

${ }^{3}$ Department of Psychology, Syracuse University, Syracuse, NY, USA

\section{Edited by:}

Karsten Lunze, Boston University, USA

\section{Reviewed by:}

Clara Van Karnebeek, University of British Columbia, Canada

Cihad Dundar, Ondokuz Mayis University, Turkey

Lucy Thairu, Touro University, USA Sarah Bagley, Boston University

Medical Center, USA

\section{*Correspondence:}

Tammy Chung, Western Psychiatric Institute and Clinic, University of

Pittsburgh Medical Center, 3811

O'Hara Street, Pittsburgh, PA 15213,

USA

e-mail: chungta@upmc.edu
Meta-analyses suggest that the serotonin transporter linked polymorphic region (5HTTLPR) short (S) allele, relative to the long (L) allele, is associated with risk for alcohol dependence, particularly among individuals with early onset antisocial alcoholism. Youth in substance use treatment tend to show antisocial or externalizing behaviors, such as conduct problems, which predict worse treatment outcome. This study examined a pathway in which 5-HTTLPR genotype is associated with externalizing behavior, and the intermediate phenotype of externalizing behavior serves as a link between 5-HTTLPR genotype and substance use treatment outcome in youth. Adolescents $(n=142)$ who were recruited from addictions treatment were genotyped for 5 -HTTLPR polymorphisms ( $\mathrm{S}$ and $\mathrm{L}_{\mathrm{G}}$ carriers vs. $L_{A} L_{A}$ ), assessed for externalizing and internalizing behaviors shortly after starting treatment, and followed over 6-months. 5-HTTLPR genotype was not associated with internalizing behaviors, and was not directly associated with 6-month substance use outcomes. However, 5-HTTLPR genotype was associated with externalizing behaviors ( $\mathrm{S}$ and $\left.L_{G}>L_{A} L_{A}\right)$, and externalizing behaviors predicted alcohol and marijuana problem severity at 6-month follow-up. Results indicated an indirect $(p<0.05)$ and non-specific (i.e., both alcohol and marijuana severity) effect of 5-HTTLPR genotype on youth substance use treatment outcomes, with externalizing behaviors as an important linking factor. Adolescents in substance use treatment with low expressing $\left(S\right.$ and $\left.L_{G}\right) 5-H T T L P R$ alleles and externalizing behavior might benefit from intervention that addresses serotonergic functioning, externalizing behaviors, and substance use to improve outcomes.

Keywords: adolescent, alcohol, externalizing behavior, genetics, marijuana, serotonin transporter

\section{INTRODUCTION}

Serotonergic functioning has been associated with externalizing behaviors, such as conduct problems and aggression; internalizing behaviors, such as depression and anxiety (1); and substance use (2). Externalizing behaviors commonly precede and predict adolescent substance use (3). Internalizing behaviors also have been linked with youth substance use, under certain conditions (4). In adolescents, serotonin transporter genotype may be more strongly associated with intermediate phenotypes of externalizing and internalizing behaviors, than with a substance use phenotype, because the intermediate phenotypes often manifest prior to substance use behavior. Among adolescents in substance use treatment, externalizing behaviors robustly predict worse outcomes (5). Based on these observations, this study of adolescent substance users tested a pathway in which serotonin transporter genotype is associated with externalizing and internalizing behaviors as intermediate phenotypes, and the intermediate phenotypes provide a link between serotonin transporter genotype and substance use treatment outcomes. Increased understanding of how a genetic marker is associated with treatment outcome could ultimately help to guide the development of personalized interventions (6).
Serotonergic functioning involves SLC6A4, a gene in the regulatory pathway for serotonin (5-HT), which encodes the 5-HT transporter (5-HTT) protein. The SLC6A4 gene has a functional polymorphism in its regulatory region, known as the 5-HTT linked promoter region (5-HTTLPR), which has two allele variants: a 44bp insertion [long (L) allele] or deletion [short (S) allele]. The S-allele is associated with a 2- to 2.5-fold decrease in 5-HTT transcription rate compared to the L-allele (7). The L-allele can be further characterized by the presence of an adenine to guanine $(A>G)$ change $(8,9)$. The L-allele with guanine $\left(L_{G}\right)$ and the $S$ allele have similar transcriptional activity, whereas the $\mathrm{L}$-allele with adenine $\left(\mathrm{L}_{\mathrm{A}}\right)$ is associated with increased transcriptional activity (10). Based on the functionality of alleles (10), studies have compared "low" vs. "high" expressing allele carriers (i.e., $\mathrm{L}_{\mathrm{A}} \mathrm{L}_{\mathrm{A}}$ vs. $\mathrm{S}$ and $\mathrm{L}_{\mathrm{G}}$ carriers $)(11,12)$.

The 5-HTTLPR short, relative to the long, allele has been associated with risk for both externalizing and internalizing behaviors $(1,13)$. Although most studies report that the 5-HTTLPR S-allele increased risk for externalizing behaviors [e.g., Ref. (14-16)], one study reported no association with conduct problems (17). In adolescents, 5-HTTLPR S-allele played a role in the association 
between internalizing behaviors and alcohol use, possibly through shared risk factors, such as stress reactivity [e.g., Ref. (4)]. There is stronger evidence of an association between serotonin transporter genotype and externalizing, than internalizing, behaviors. Mixed findings for externalizing behaviors may be due, in part, to the need to account for high vs. low expressing 5-HTTLPR L-allele subtypes $\left(\mathrm{L}_{\mathrm{A}}\right.$ and $\left.\mathrm{L}_{\mathrm{G}}\right)$.

With regard to substance use, the S-allele was associated with slightly increased odds of alcohol dependence in two metaanalyses $(18,19)$. Importantly, the S-allele was more common among individuals with an early onset, severe form of alcoholism associated with antisocial features (18). Further, a study of adolescents found that the S-allele was associated with the early development of alcohol use [e.g., Ref. (20)]. These findings suggest that the association between 5-HTTLPR genotype and alcohol involvement may occur through a pathway that involves externalizing behavior as an intermediate phenotype $(1,16,21)$.

Few studies have examined 5-HTTLPR genotype in relation to substance use treatment outcome. In a study of African American cocaine and alcohol abusers, S-allele homozygotes showed less improvement on drinking measures at 6-month follow-up (22). Another study found that the 5-HTTLPR S-allele was associated with relapse to alcohol over 3-month follow-up among Caucasian males treated for alcohol dependence (23). The study of treated alcohol dependent males discussed the possibility that the 5-HTTLPR S-allele does not directly influence substance use relapse, but may have effects on outcome through an intermediate phenotype involving impaired behavioral control, as manifested by externalizing behaviors. No study has examined whether 5HTTLPR genotype has an indirect effect on treatment outcome through intermediate phenotypes of externalizing or internalizing behaviors.

This study addresses gaps in knowledge regarding 5-HTTLPR genotype as a predictor of adolescent substance use treatment outcome. We hypothesized, as suggested by research with treated adults (23), that 5-HTTLPR genotype would be indirectly associated with adolescent posttreatment alcohol and marijuana problem severity through the intermediate phenotype of externalizing behavior. Specifically, $\mathrm{S} / \mathrm{L}_{\mathrm{G}}$ allele carriers, relative to $\mathrm{L}_{\mathrm{A}}$ homozygotes, were predicted to report greater externalizing behavior [see Ref. (24)], and greater externalizing behavior was predicted to be associated with greater alcohol and marijuana problem severity at 6-month follow-up [see Ref. (5)] (see Figure 1).

\section{MATERIALS AND METHODS \\ PARTICIPANTS}

In the United States, $6.1 \%$ of youth (ages 12-17) met criteria for a DSM-IV alcohol or illicit drug use disorder in the past year (25). The prevalence of past year substance use disorder in the urban setting of Pittsburgh, PA, USA is similar to national prevalence rates (26). This study recruited 209 adolescents (ages 14-18) from community-based substance use treatment in Pittsburgh. Of the 209 youth, $153(73.2 \%)$ youth were successfully genotyped $(n=55$ did not provide DNA, $n=1$ sample could not be genotyped). Cases with missing data due to incomplete baseline questionnaires $(n=11)$ were excluded, resulting in a baseline analysis sample of 142 adolescents. Youth who were vs. were not included in the

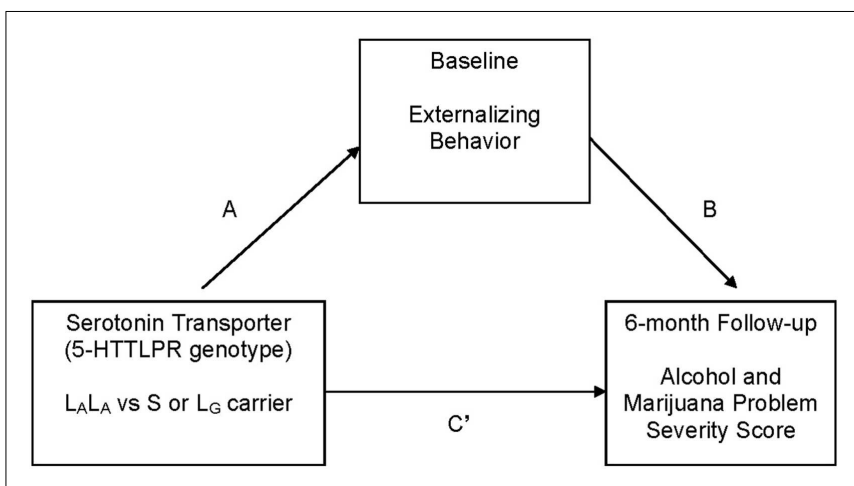

FIGURE 1 | Hypothesized mediation (indirect effects) model that was tested. $C^{\prime}$ represents the direct effect of independent variable (5-HTTLPR genotype: high vs. low expressing) on the dependent variable (alcohol and marijuana problem severity at 6 months) after controlling for the intervening variable (externalizing behavior). The $\mathrm{C}$ path (not labeled in the figure) represents the total effect of the independent variable on the dependent variable. Covariates: gender, age, race (Caucasian vs. all other ethnicity), socio-economic status, and baseline frequency of substance use.

analysis sample did not differ $(p>0.10)$ on demographic characteristics (age, gender, race, and SES) or frequency of using alcohol or marijuana at baseline.

The analysis sample was $66.2 \%$ male. Based on self-reported race/ethnic identity, the sample was $86.6 \%$ Caucasian, $7.0 \%$ African American, and 6.3\% other ethnicity (e.g., bi-racial). Average age was $16.7(\mathrm{SD}=1.2)$. Sample demographic characteristics (Table 1) were similar to those of youth admitted to publicly funded substance use treatment (27). Participants were, on average, middle-class in socio-economic status $[$ mean $=2.4, \mathrm{SD}=1.1$; range $=1-5 ;(28)]$. Most $(85.9 \%)$ had a current (past 6 months) DSM-IV cannabis use disorder, and almost half (47.2\%) had a current DSM-IV alcohol use disorder. Six-month follow-up data were available for $89 \%(n=126)$ of the sample; those who did vs. those who did not complete follow-up did not differ on demographics, internalizing or externalizing symptoms, and baseline alcohol or marijuana problem severity $(p>0.15)$.

\section{PROCEDURE}

Youth admitted to community-based intensive outpatient substance use treatment were approached to participate in a longitudinal study on treatment outcome $(29,30)$. Treatment involved three 3-h group sessions per week for 6-8 weeks, with content that supported a goal of abstinence from alcohol and illicit drugs. Informed consent (from 18 years olds) or assent (from minors, with informed consent for the minor's participation provided by the minor's parent) was obtained prior to initiating study procedures. The baseline assessment, which was typically completed within 2 weeks of treatment entry, collected substance use and psychiatric data. The same domains were assessed at follow-up. Baseline data were collected from 2004 to 2009. Highly trained research associates collected interview data with high reliability (31), and saliva DNA according to protocol. Youth completed questionnaires at home, which were returned at the interview session or by mail. The University of Pittsburgh's Institutional Review Board approved the study protocol (no. IRB0402001). 
Table 1 | Descriptive statistics for the total sample, and high vs. low expressing allele groups.

\begin{tabular}{|c|c|c|c|c|c|c|}
\hline \multirow[b]{2}{*}{ Demographics } & \multicolumn{2}{|c|}{ Total } & \multicolumn{2}{|c|}{ High exp } & \multicolumn{2}{|c|}{ Low exp } \\
\hline & $n$ & $\%$ & $n$ & $\%$ & $n$ & $\%$ \\
\hline Female & 48 & 33.8 & 11 & 31.4 & 37 & 34.6 \\
\hline Male & 94 & 66.2 & 24 & 68.6 & 70 & 65.4 \\
\hline \multicolumn{7}{|l|}{ Ethnicity } \\
\hline Caucasian & 123 & 86.6 & 28 & 80.0 & 95 & 88.8 \\
\hline African American & 10 & 7.0 & 3 & 8.6 & 7 & 6.5 \\
\hline Multi-racial & 9 & 6.3 & 4 & 11.4 & 5 & 4.7 \\
\hline Baseline & \multicolumn{2}{|c|}{ Mean (SD) } & \multicolumn{2}{|c|}{ Mean (SD) } & \multicolumn{2}{|c|}{ Mean (SD) } \\
\hline Age & \multicolumn{2}{|c|}{$16.7(1.2)$} & \multicolumn{2}{|c|}{$16.7(1.2)$} & \multicolumn{2}{|c|}{$16.7(1.2)$} \\
\hline Socio-economic status (28) & \multicolumn{2}{|c|}{$2.5(1.1)$} & \multicolumn{2}{|c|}{$2.5(1.2)$} & \multicolumn{2}{|c|}{$2.5(1.1)$} \\
\hline Externalizing composite $T$ score & \multicolumn{2}{|c|}{$62.1(13.4)$} & \multicolumn{2}{|c|}{$57.2(13.5)$} & \multicolumn{2}{|c|}{$63.7(13.0)$} \\
\hline Internalizing composite $T$ score & \multicolumn{2}{|c|}{$52.1(13.4)$} & \multicolumn{2}{|c|}{$49.1(14.6)$} & \multicolumn{2}{|c|}{$53.2(12.9)$} \\
\hline \multicolumn{7}{|l|}{ Frequency of substance use (past 6-months) } \\
\hline Alcohol use & \multicolumn{2}{|c|}{$3.6(1.9)$} & \multicolumn{2}{|c|}{$3.3(1.9)$} & \multicolumn{2}{|c|}{$3.7(1.9)$} \\
\hline \multirow[t]{2}{*}{ Marijuana use } & \multicolumn{2}{|c|}{$5.6(2.5)$} & \multicolumn{2}{|c|}{$5.6(2.8)$} & \multicolumn{2}{|c|}{$5.7(2.3)$} \\
\hline & $n$ & $\%$ & $n$ & $\%$ & $n$ & $\%$ \\
\hline Current DSM-IV alcohol use disorder & 67 & 47.2 & 13 & 37.1 & 54 & 50.5 \\
\hline Alcohol abuse & 54 & 38.0 & 11 & 31.4 & 43 & 40.2 \\
\hline Alcohol dependence & 13 & 9.2 & 2 & 5.7 & 11 & 10.3 \\
\hline Current DSM-IV cannabis use disorder & 122 & 85.9 & 27 & 77.1 & 95 & 88.8 \\
\hline Cannabis abuse & 73 & 51.4 & 20 & 57.1 & 53 & 49.5 \\
\hline Cannabis dependence & 49 & 34.5 & 7 & 20.0 & 42 & 39.3 \\
\hline \multicolumn{7}{|l|}{ Current DSM-IV psychopathology } \\
\hline Conduct disorder & 53 & 37.3 & 13 & 37.1 & 40 & 37.4 \\
\hline Attention deficit hyperactivity disorder & 50 & 35.2 & 7 & 20.0 & 43 & 40.2 \\
\hline Major depression & 20 & 14.1 & 7 & 20.0 & 13 & 12.1 \\
\hline 6-month Follow-up (time frame: past 6 months) & & & & & & \\
\hline Frequency of substance use ${ }^{a}$ & & & & & & \\
\hline Alcohol use & & & & & & \\
\hline Marijuana use & & & & & & \\
\hline Rutgers alcohol problems index score & & & & & & \\
\hline Rutgers marijuana problems index score & & & & & & \\
\hline
\end{tabular}

Baseline $N=142 ; 6$-month $n=126$; high exp, high expressing $\left(L_{A} L_{A}, n=35\right)$; low exp, low expressing $\left(S\right.$ and $\left.L_{G}, n=107\right)$; $B L$, baseline; $S D$, standard deviation; current, past 6 months.

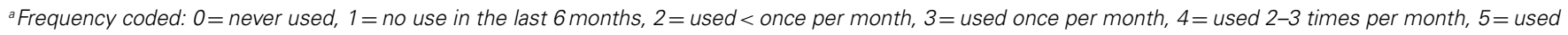
once per week, 6= used 2-3 times per week, 7= used 4-6 times per week, and 8= daily use.

\section{DNA COLLECTION AND GENOTYPING}

DNA from saliva was collected using a mouthwash protocol (32). Samples were subjected to whole genome amplification using multiple displacement amplification (33), quantified by the pico green protocol, and diluted to $40 \mathrm{ng} / \mu \mathrm{l}$ for storage. A polymerase chain reaction protocol followed by double restriction endonuclease digestion was used to identify the 5-HTTLPR (SLC6A4) and rs25531 variants: $S, L_{A}$, and $L_{G}(9)$. The primer sequences were: (forward) $5^{\prime}$-TCCTCCGCTTTGGCGCCTCTTCC-3', and (reverse) 5' -TGGGGGTTGCAGGGGAGATCCTG-3'. The L-allele was subtyped for rs25531. The A > G SNP of rs25531 was concurrently detected by digesting the amplified fragments with MspI (New England Biolabs, Beverly, MA, USA), where the A > G substitution creates an additional MspI site. Amplification products were simultaneously resolved by electrophoresis on 3.5\% agarose gels.

The genotype distribution in the total sample $(N=142)$ was: $\mathrm{SS}, \quad n=19$ (13.4\%); $\mathrm{SL}_{\mathrm{G}}, n=9$ (6.3\%); $\mathrm{L}_{\mathrm{G}} \mathrm{L}_{\mathrm{G}}, \quad n=2$ (1.4\%); $\mathrm{SL}_{\mathrm{A}}, n=60(42.3 \%) ; \mathrm{L}_{\mathrm{G}} \mathrm{L}_{\mathrm{A}}, n=17(12.0 \%)$; and $\mathrm{L}_{\mathrm{A}} \mathrm{L}_{\mathrm{A}}$, $n=35(24.6 \%)$. SS, SL, and LL frequencies did not deviate 
significantly from Hardy-Weinberg equilibrium in the total sample $\left(\chi^{2}[\mathrm{df}=1]=0.17\right)$, or in the Caucasian subsample ${ }^{1}(N=123$ : SS $n=18$, SL $n=65$, LL $\left.n=40 ; \chi^{2}[\mathrm{df}=1]=1.04\right)$. As in prior studies [see Ref. (8)], "low" expressing $S$ and $L_{G}$ alleles were grouped together and compared with "high" expressing $\mathrm{L}_{\mathrm{A}}$ allele (total sample: $\mathrm{L}_{\mathrm{A}} \mathrm{L}_{\mathrm{A}} n=35$ vs. all other types $n=107$; Caucasian: $\mathrm{L}_{\mathrm{A}} \mathrm{L}_{\mathrm{A}} n=28$ vs. all other types $\left.n=95\right)$.

\section{MEASURES OF SUBSTANCE INVOLVEMENT AND PSYCHOPATHOLOGY}

An adapted structured clinical interview for DSM-IV SUDs [SCID; (34) ] assessed past 6-month SUD diagnoses at baseline and followup. The adapted SCID has acceptable reliability and validity (31). The Kiddie-schedule for affective disorders and schizophrenia (35) assessed current DSM-IV psychopathology.

The youth self-report (YSR; ages 14-17, 112 items) or young adult self-report (YASR; age 18, 116 items) $(36,37)$ was completed at baseline. Items used a 6-month time frame, with responses coded as "not true," "sometimes true," or "often true." A normalized $T$ score was computed for the internalizing (withdrawn, somatic complaints, and anxious/depressed subscales) and externalizing (delinquent behavior and aggressive behavior subscales) composite indices. The externalizing composite score includes items on substance use (e.g., "I use drugs for non-medicinal purposes").

The drug consumption questionnaire assessed frequency of alcohol and marijuana use in the past 6 months at each assessment using a 9 -point scale $(0=$ never used, $1=$ no use in the last 6 months, $2=$ used less than once per month, $3=$ used once per month, $4=$ used 2-3 times per month, $5=$ used once per week, $6=$ used 2-3 times per week, $7=$ used 4-6 times per week, and $8=$ daily). The substance use frequency items have satisfactory reliability and validity (31).

The Rutgers alcohol problem index [RAPI; (38)] and Rutgers marijuana problem index [RMPI; (39)], which each include 18 items rated on a $0-4$ scale $(0=0$ times, $1=1-2$ times, $2=3-$ 5 times, $3=6-10$ times, and $4 \geq 10$ times), assessed alcohol and marijuana problem severity at 6-month follow-up (RAPI alpha $=0.91$; RMPI alpha $=0.92)$. RAPI and RMPI scores were positively correlated $(r=0.67, p=0.001)$.

\section{DATA ANALYSIS}

Bivariate correlations were run as a preliminary step to determine the utility of testing hypothesized mediation (indirect) effect models (40). Tests for indirect effect used a bootstrapping procedure (5,000 resamples) available as an SPSS macro (41). Each model (see Figure 1; Table 2) tested an "A path," which represents the path from the independent variable (serotonin transporter genotype) to the intervening variable (e.g., externalizing score); a "B path," which represents the direct effect of the intervening variable (e.g., externalizing score) on the dependent variable (baseline RAPI/RMPI score); a "C path," which represents the total effect of the independent variable on the dependent variable; and a " $\mathrm{C}^{\prime}$ path," which represents the direct effect of the independent variable on the dependent variable,

\footnotetext{
${ }^{1}$ The genotype distribution in the Caucasian sample $(N=123)$ was: SS, $n=18$ $(14.6 \%) ; \mathrm{SL}_{\mathrm{G}}, n=9(7.3 \%) ; \mathrm{L}_{\mathrm{G}} \mathrm{L}_{\mathrm{G}}, n=2(1.6 \%) ; \mathrm{SL}_{\mathrm{A}}, n=56(45.5 \%) ; \mathrm{L}_{\mathrm{G}} \mathrm{L}_{\mathrm{A}}, n=10$ (8.1\%); and $\mathrm{L}_{\mathrm{A}} \mathrm{L}_{\mathrm{A}}, n=28(22.8 \%)$.
}

Table 2 | Parameter estimates for models, testing indirect effects of externalizing symptoms on the association between serotonin transporter genotype (A/G) and 6-month RAPI and RMPI score

\begin{tabular}{lrrrr}
\hline \multicolumn{1}{c}{$\boldsymbol{B}$} & SE & $\boldsymbol{t}$ & $\boldsymbol{p}$ \\
\hline \multicolumn{1}{l}{ OUTCOME: 6-month RAPI } & & & & \\
A path & 6.69 & 2.60 & 2.57 & 0.011 \\
B path & 0.24 & 0.07 & 3.46 & 0.001 \\
C path & 1.33 & 2.07 & 0.64 & 0.523 \\
C' $^{\prime}$ path & -0.29 & 2.03 & -0.14 & 0.885 \\
Covariates: gender & 3.28 & 1.83 & 1.79 & 0.076 \\
Age & -0.34 & 0.73 & -0.46 & 0.642 \\
Race & 0.06 & 2.69 & 0.02 & 0.983 \\
SES & 1.35 & 0.81 & 1.66 & 0.098 \\
BL alcohol days & 1.48 & 0.46 & 3.21 & 0.002 \\
\end{tabular}

Indirect effect point estimate $=1.62$ (BCa 95\% Cl: 0.36, 3.84).

Model summary: $n=125 ; R^{2}=0.19, F(7,117)=4.03, p=0.0005$.

\begin{tabular}{lllll}
\multicolumn{2}{l}{ OUTCOME: 6-month RMPI } & & & \\
A path & 6.44 & 2.66 & 2.42 & 0.017 \\
B path & 0.28 & 0.09 & 3.09 & 0.002 \\
C path & 4.88 & 2.71 & 1.80 & 0.075 \\
C' path $^{\prime}$ Covariates: gender & 3.05 & 2.68 & 1.13 & 0.259 \\
$\quad$ Age & 6.07 & 2.46 & 2.47 & 0.015 \\
Race & 0.09 & 0.94 & 0.10 & 0.922 \\
SES & 1.86 & 3.46 & 0.54 & 0.592 \\
BL marijuana days & 1.35 & 1.05 & 1.28 & 0.202 \\
\hline
\end{tabular}

Indirect effect point estimate $=1.83$ (BCa 95\% Cl: 0.39, 4.17).

Model summary: $n=122 ; R^{2}=0.20, F(7,114)=4.18, p=0.0004$.

BL, baseline; 6-mo, 6-month follow-up; RAPI, Rutgers alcohol problems inventory; RMPI, Rutgers marijuana problems inventory; alcohol/marijuana days, number of use days in the month prior to BL; $B$, unstandardized coefficient; $S E$, standard error; gender $10=$ female, $1=$ male); race $(0=$ other race/ethnicity, $1=$ Caucasian); SES, socio-economic status (1-5, 1= high SES). A path, independent variable (serotonin transporter genotype: $0=L_{A} L_{A}, 1=S / L_{G}$ carrier) to intervening variable (externalizing score); $B$ path, direct effect of intervening variable (externalizing score) on dependent variable (6-month RAPI/RMPI score); C path, total effect of independent variable on dependent variable; $C$ path, direct effect of independent variable on dependent variable, after controlling for the intervening variable. Covariates: partial effect of covariates on dependent variable.

after controlling for the intervening variable. A significant indirect effect in the regression model is indicated when the $95 \%$ bias-corrected and accelerated (BCa) confidence interval around the unstandardized coefficient does not include 0 (41). An indirect effect can be detected in the absence of a significant direct effect [e.g., Ref. $(40,42)]$. Regression analyses controlled for gender, age, race (i.e., Caucasian vs. other race), socio-economic status, and baseline substance use. There was no difference in the pattern of results using transformed and untransformed variables, so results using untransformed data are reported [see Ref. (43)]. Because 5-HTTLPR allele frequencies differ across race (44), we conducted secondary analyses only in the Caucasian subsample. 


\section{RESULTS}

\section{COMPARISON OF HIGH vs. LOW EXPRESSING ALLELE GROUPS}

In the total sample (see Table 1 for descriptives), 5-HTTLPR genotype $\left(0=\mathrm{L}_{\mathrm{A}} \mathrm{L}_{\mathrm{A}}, 1=\mathrm{S}\right.$ or $\mathrm{L}_{\mathrm{G}}$ allele carrier) was not associated with a current DSM-IV alcohol, marijuana, major depression, or conduct disorder diagnosis at baseline $(p=0.17,0.09,0.25$, and 0.98 , respectively). However, the low, compared to high, expressing allele group was more likely to have current DSM-IV ADHD at baseline $\left(\chi^{2}=4.71, \mathrm{df}=1, p<0.05\right.$; also observed in only the Caucasian subsample: $\left.\chi^{2}=5.06, \mathrm{df}=1, p<0.05\right)$. High vs. low expressing genotype did not differ on internalizing score $(p>0.10)$, or frequency of alcohol use (at baseline $p>0.20$ or 6 -month follow-up $p>0.10$ ) and marijuana use (at baseline $p>0.75$ or 6 -month follow-up $p>0.09)$. However, the high, relative to low, expressing genotype had a higher externalizing score $(t=-2.56$, $\mathrm{df}=140, p=0.01$; also observed in only the Caucasian subsample: $t=-2.33, \mathrm{df}=121, p=0.02)$.

\section{TESTING AN INDIRECT PATHWAY LINKING 5-HTTLPR GENOTYPE AND TREATMENT OUTCOME}

Preliminary bivariate correlations supported a possible mediation ("indirect") pathway involving an association between 5HTTLPR low vs. high expressing genotype and externalizing behavior $(r=0.21, p=0.01)$, and externalizing behavior with 6month alcohol and marijuana-related problems (RAPI $r=0.30$, $p<0.01$; RMPI $=0.27, p<0.01)$. These correlations held in the Caucasian subsample $(p<0.05)$. Thus, indirect effect analyses focus on the association between 5-HTTLPR genotype, externalizing behavior, and 6-month RAPI and RMPI scores (see Figure 1).

In predicting 6-month RAPI score (Table 2), 5-HTTLPR genotype was associated with externalizing behavior $(B=6.69$, $p=0.01$; low expressing group was associated with greater externalizing behavior), and externalizing behavior was positively associated with 6-month RAPI score $(B=0.24, p=0.001)$. 5HTTLPR genotype was not directly associated with 6-month RAPI $(B=1.33, p=0.52)$. A significant indirect effect linking 5-HTTLPR genotype to 6-month RAPI scores through externalizing behavior, adjusting for covariates, was observed: point estimate $=1.62($ BCa 95\% CI: 0.36, 3.84).

For the model predicting 6-month RMPI score, the low expressing group was associated with greater externalizing behavior $(B=6.44, p=0.02)$, and externalizing behavior was positively associated with 6-month RMPI score $(B=0.28, p=0.002)$. 5HTTLPR genotype was not directly associated with 6-month RMPI $(B=4.88, p=0.08)$. An indirect effect of externalizing behavior in the association between 5-HTTLPR genotype and 6month RMPI score was observed: point estimate $=1.83$ (BCa 95\% CI: $0.39,4.17)$.

Analyses of the Caucasian subsample, adjusting for covariates, yielded similar results regarding indirect effects of externalizing behavior score in the association between 5-HTTLPR genotype and 6-month RAPI and RMPI scores: RAPI point estimate $=1.66$ (BCa 95\% CI: 0.34, 4.25); RMPI point estimate $=1.98(\mathrm{BCa} 95 \%$ CI: $0.39,4.79)$.

\section{DISCUSSION}

Results supported the hypothesis that low, relative to high, expressing 5-HTTLPR genotype would be associated with greater externalizing behavior among youth in substance use treatment. Further, 5-HTTLPR genotype was associated with treatment outcome only indirectly, through externalizing behavior. These results are applicable mainly to Caucasian youth in substance use treatment. The finding that the direct association between 5-HTTLPR genotype and 6-month alcohol and marijuana problem severity was not significant, suggests that externalizing behaviors provide an important link in the pathway between 5-HTTLPR genotype and 6-month substance use treatment outcome in this adolescent sample.

The association between 5-HTTLPR genotype and externalizing behaviors in an adolescent treatment sample is consistent with the stronger association between low expressing 5-HTTLPR genotype and alcoholism among adults with early onset, antisocial alcoholism (i.e., type II) (18), and with externalizing behaviors more generally (45). In this adolescent sample, the stronger association between 5-HTTLPR genotype and externalizing behavior, relative to a substance use phenotype (e.g., DSM-IV alcohol use disorder), may reflect that the sample has not passed through young adulthood, a period of high risk for the onset of substance use disorder.

The absence of an association between 5-HTTLPR genotype and internalizing behaviors in this study may reflect the relatively low prevalence of mood and anxiety disorders in this sample. Further, the association of ADHD with low expressing alleles observed in this study differs from other work, which reported associations between the L-allele and ADHD [e.g., Ref. (46)]. The disparate findings obtained in this study relative to prior research might be explained, for example, by specific patterns of co-occurring psychopathology in a given sample, interactions among genes (e.g., epistasis) and haplotypes [e.g., Ref. (47)], and effects of environmental conditions that were not examined.

Results are generally consistent with adult treatment studies, which found that the 5-HTTLPR S-allele was directly associated with worse outcome $(22,23)$. The current study provides a unique contribution in finding that low expressing 5-HTTLPR alleles were only indirectly linked with alcohol- and marijuana-related problems at 6-month follow-up in treated youth, through severity of externalizing behavior. These novel results in a sample of youth in substance use treatment tentatively suggest that 5-HTTLPR genotype, which was associated with externalizing behavior, might provide a possible target for treatment related to serotonergic functioning and externalizing behavior [see Ref. (48)].

The mixed findings in the literature regarding associations of low expressing 5-HTTLPR genotypes with externalizing and substance use phenotypes urge caution in the interpretation of this study's results. Although study findings are consistent with research reporting that low, relative to high, expressing alleles are associated with externalizing behavior and substance use, and other studies have found the opposite pattern. For example, low level of alcohol response in men, which is associated with alcohol dependence, was correlated with high expressing 5-HTTLPR 
genotypes ( $\mathrm{L}_{\mathrm{A}}$ homozygotes) (8), suggesting that an association between the L-allele and alcohol dependence may be specific to certain subgroups (18), and differ by gender (49). The mixed findings across studies might reflect differences in sample ascertainment and phenotype definition, and whether co-occurring psychiatric conditions, and L-allele subtypes and haplotypes were examined (50).

This study had limitations. The majority of participants were Caucasian, male, and in substance use treatment (primarily for cannabis use disorder), which limits generalizability. Sample size overall was limited. Analyses did not correct for multiple comparisons, and results require replication. A comparison group of adolescents with no substance use problems was not examined. Measures of more narrowly defined phenotypes (e.g., response inhibition), which may underlie externalizing behaviors, were not examined. Haplotype analyses were not done. Only one candidate region of the SLC6A4 gene was examined. Ideally, whole exome sequencing of all genes involved in serotonergic metabolism would be conducted to rule out rare variants, which could bias results by exerting a stronger effect on the phenotype than HTTLPR length alone.

Youth with low expressing 5-HTTLPR genotype and externalizing behaviors may benefit from interventions that address serotonergic functioning [see Ref. (48)], and intensive treatment that simultaneously aims to reduce externalizing behaviors and substance use [e.g., Ref. (51)]. However, further research is needed to more precisely identify relevant treatment targets, and to replicate results. With regard to public health implications, predictive and diagnostic genetic testing for psychiatric conditions is promising, yet premature, given mixed findings and relatively small effects of common genetic variants (52). However, greater understanding of single gene effects, based on multiple methods (e.g., whole exome sequencing, model systems) and converging results, is critical to characterizing the pathophysiology of complex diseases, which could ultimately guide the development of novel treatments for substance use (6).

\section{ACKNOWLEDGMENTS}

Support for the conduct of the research and preparation of the manuscript was provided by funding from the National Institute on Alcohol Abuse and Alcoholism (R01 AA014357, K02 AA018195, R21 AA017128, R01 AA13397, U01AA021690) and National Institute on Drug Abuse (P50 DA005605).

\section{REFERENCES}

1. Carver CS, Johnson SL, Joormann J. Two-mode models of self-regulation as a tool for conceptualizing effects of the serotonin system in normal behavior and diverse disorders. Curr Dir Psychol Sci (2009) 18(4):195-9. doi:10.1111/j.14678721.2009.01635.x

2. Kreek MJ, Nielsen DA, Butelman ER, LaForge KS. Genetic influences on impulsivity, risk taking, stress responsivity and vulnerability to drug abuse and addiction. Nat Neurosci (2005) 8(11):1450-7. doi:10.1038/nn1583

3. Zucker RA, Heitzeg MM, Nigg JT. Parsing the undercontrol/disinhibition pathway to substance use disorders: a multilevel developmental problem. Child Dev Perspect (2011) 5(4):248-55. doi:10.1111/j.1750-8606.2011.00172.x

4. Saraceno L, Munafo M, Heron J, Craddock N, van den Bree MB. Genetic and non-genetic influences on the development of co-occurring alcohol problem use and internalizing symptomatology in adolescence: a review. Addiction (2009) 104(7):1100-21. doi:10.1111/j.1360-0443.2009.02571.x
5. Chung T, Maisto SA. Relapse to alcohol and other drug use in treated adolescents: review and reconsideration of relapse as a change point in clinical course. Clin Psychol Rev (2006) 26(2):149-61. doi:10.1016/j.cpr.2005.11.004

6. Perlis RH. Can single genes matter in a polygenic world? Biol Psychiatry (2010) 68:783-4. doi:10.1016/j.biopsych.2010.09.010

7. Lesch KP, Bengel D, Heils A, Sabol SZ, Greenberg BD, Petri S, et al. Association of anxiety-related traits with a polymorphism in the serotonin transporter gene regulatory region. Science (1996) 274(5292):1527-31. doi:10.1126/science.274. 5292.1527

8. Hu X, Oroszi G, Chun J, Smith TL, Goldman D, Schuckit MA. An expanded evaluation of the relationship of four alleles to the level of response to alcohol and the alcoholism risk. Alcohol Clin Exp Res (2005) 29(1):8-16. doi:10.1097/01.ALC.0000150008.68473.62

9. Wendland JR, Martin BJ, Kruse MR, Lesch KP, Murphy DL. Simultaneous genotyping of four functional loci of human SLC6A4, with a reappraisal of 5HTTLPR and rs25531. Mol Psychiatry (2006) 11(3):224-6. doi:10.1038/sj.mp. 4001789

10. Hu XZ, Lipsky RH, Zhu G, Akhtar LA, Taubman J, Greenberg BD, et al. Serotonin transporter promoter gain-of-function genotypes are linked to obsessivecompulsive disorder. Am J Hum Genet (2006) 78(5):815-26. doi:10.1086/503850

11. Beevers CG, Marti CN, Lee HJ, Stote DL, Ferrell RE, Hariri AR, et al. Associations between serotonin transporter gene promoter region (5-HTTLPR) polymorphism and gaze bias for emotional information. J Abnorm Psychol (2011) 120(1):187-97. doi:10.1037/a0022125

12. Fox E, Zougkou K, Ridgewell A, Garner K. The serotonin transporter gene alters sensitivity to attention bias modification: evidence for a plasticity gene. Biol Psychiatry (2011) 70(11):1049-54. doi:10.1016/j.biopsych.2011.07.004

13. Carver CS, Johnson SL, Joormann J. Serotonergic function, two-mode models of self-regulation, and vulnerability to depression: what depression has in common with impulsive aggression. Psychol Bull (2008) 134(6):912-43. doi:10.1037/a0013740

14. Haberstick BC, Smolen A, Hewitt JK. Family-based association test of the 5HTTLPR and aggressive behavior in a general population sample of children. Biol Psychiatry (2006) 59(9):836-43. doi:10.1016/j.biopsych.2005.10.008

15. Sakai JT, Young SE, Stallings MC, Timberlake D, Smolen A, Stetler GL, et al. Casecontrol and within-family tests for an association between conduct disorder and 5HTTLPR. Am J Med Genet B Neuropsychiatr Genet (2006) 141B(8):825-32. doi:10.1002/ajmg.b.30278

16. Cadoret RJ, Langbehn D, Caspers K, Troughton EP, Yucuis R, Sandhu HK, et al. Associations of the serotonin transporter promoter polymorphism with aggressivity, attention deficit, and conduct disorder in an adoptee population. Compr Psychiatry (2003) 44(2):88-101. doi:10.1053/comp.2003.50018

17. Sakai JT, Boardman JD, Gelhorn HL, Smolen A, Corley RP, Huizinga D, et al. Using trajectory analyses to refine phenotype for genetic association: conduct problems and the serotonin transporter (5HTTLPR). Psychiatr Genet (2010) 20(5):199-206. doi:10.1097/YPG.0b013e32833a20f1

18. Feinn R, Nellissery M, Kranzler HR. Meta-analysis of the association of a functional serotonin transporter promoter polymorphism with alcohol dependence. Am J Med Genet B Neuropsychiatr Genet (2005) 133B(1):79-84. doi:10.1002/ ajmg.b.30132

19. McHugh RK, Hofmann SG, Asnaani A, Sawyer AT, Otto MW. The serotonin transporter gene and risk for alcohol dependence: a meta-analytic review. Drug Alcohol Depend (2010) 108(1-2):1-6. doi:10.1016/j.drugalcdep.2009.11.017

20. van der Zwaluw CS, Engels RC, Vermulst AA, Rose RJ, Verkes RJ, Buitelaar J, et al. A serotonin transporter polymorphism (5-HTTLPR) predicts the development of adolescent alcohol use. Drug Alcohol Depend (2010) 112(1-2):134-9. doi:10.1016/j.drugalcdep.2010.06.001

21. Gerra G, Garofano L, Santoro G, Bosari S, Pellegrini C, Zaimovic A, et al. Association between low-activity serotonin transporter genotype and heroin dependence: behavioral and personality correlates. Am J Med Genet B Neuropsychiatr Genet (2004) 126B(1):37-42. doi:10.1002/ajmg.b.20111

22. Mannelli P, Patkar AA, Murray HW, Certa K, Peindl K, Mattila-Evenden M, et al. Polymorphism in the serotonin transporter gene and response to treatment in African American cocaine and alcohol-abusing individuals. Addict Biol (2005) 10(3):261-8. doi:10.1080/13556210500235540

23. Pinto E, Reggers J, Gorwood P, Boni C, Scantamburlo G, Pitchot W, et al. The short allele of the serotonin transporter promoter polymorphism influences relapse in alcohol dependence. Alcohol Alcohol (2008) 43(4):398-400. doi:10.1093/alcalc/agn015 
24. Reese J, Kraschewski A, Anghelescu I, Winterer G, Schmidt LG, Gallinat J, et al. Haplotypes of dopamine and serotonin transporter genes are associated with antisocial personality disorder in alcoholics. Psychiatr Genet (2010) 20(4):140-52. doi:10.1097/YPG.0b013e32833alecb

25. Substance Abuse and Mental Health Services Administration. Results from the 2012 National Survey on Drug Use and Health: Summary of National Findings. Rockville, MD: Department of Health and Human Services (2013).

26. Substance Abuse and Mental Health Services Administration. Substance Use and Mental Disorders in Metropolitan Areas: Results from the 2005-2010 National Survey on Drug Use and Health (2010). Available from: http://www.samhsa.gov/ data/NSDUHMetroBriefReports/index.aspx

27. Substance Abuse and Mental Health Services Administration. Treatment Episode Data Set (TEDS) 1999-2009: National Admissions to Substance Abuse Treatment Services (Vol. DASIS Series: S-56 (SMA) 11-4646). Rockville, MD: Substance Abuse and Mental Health Services Administration (2011).

28. Hollingshead AB. Four Factor Index of Social Status. New Haven, CT: Hollingshead AB (1975).

29. King KM, Chung T, Maisto SA. Adolescents' thoughts about abstinence curb the return of marijuana use during and after treatment. J Consult Clin Psychol (2009) 77(3):554-65. doi:10.1037/a0015391

30. Maisto SA, Krenek M, Chung T, Martin CS, Cornelius JR, Clark DB. Comparison of the concurrent and predictive validity of three measures of readiness to change alcohol use in a clinical sample. Psychol Assess (2011) 23:983-94. doi: $10.1037 / \mathrm{a} 0024136$

31. Chung T, Martin CS, San Pedro R, Shriberg RF, Cornelius JR. Retest reliability and discrepancy interview for DSM-IV alcohol, cannabis, and nicotine diagnoses in treated adolescents. Alcohol Clin Exp Res (2004) 28(5 Suppl):111.

32. King IB, Satia-Abouta J, Thornquist MD, Bigler J, Patterson RE, Kristal AR, et al. Buccal cell DNA yield, quality, and collection costs: comparison of methods for large-scale studies. Cancer Epidemiol Biomarkers Prev (2002) 11(10 Pt 1): $1130-3$.

33. Dean FB, Hosono S, Fang L, Wu X, Faruqi AF, Bray-Ward P, et al. Comprehensive human genome amplification using multiple displacement amplification. Proc Natl Acad Sci U S A (2002) 99(8):5261-6. doi:10.1073/pnas.082089499

34. First MB, Spitzer RL, Gibbon M, Williams JB. Structured Clinical Interview for DSM-IV-TR Axis I Disorders. New York, NY: Biometrics Research, New York State Psychiatric Institute (2002).

35. Kaufman J, Birmaher B, Brent D, Rao U, Flynn C, Moreci P, et al. Schedule for affective disorders and schizophrenia for school-age children-present and lifetime version (K-SADS-PL): initial reliability and validity data. J Am Acad Child Adolesc Psychiatry (1997) 36(7):980-8. doi:10.1097/00004583199707000-00021

36. Achenbach TM. Manual for the Youth Self-Report and Profile. Burlington: University of Vermont (1991).

37. Achenbach TM. Young Adult Self-Report. Burlington: University of Vermont (1997).

38. White HR, Labouvie EW. Towards the assessment of adolescent problem drinking. J Stud on Alcohol (1989) 50(1):30-7.

39. White HR, Labouvie EW, Papadaratsakis V. Changes in substance use during the transition to adulthood: a comparison of college students and their noncollege age peers. J Drug Issues (2005) 35:281-306. doi:10.1177/ 002204260503500204

40. MacKinnon DP. Introduction to Statistical Mediation Analysis. New York, NY: Lawrence Erlbaum (2008).
41. Preacher KJ, Hayes AF. SPSS and SAS procedures for estimating indirect effects in simple mediation models. Behav Res Methods Instrum Comput (2004) 36(4):717-31. doi:10.3758/BF03206553

42. Hayes AF. Beyond Baron and Kenny: statistical mediation in the new millennium. Commun Monogr (2009) 76(4):408-20. doi:10.1080/03637750903310360

43. Tabachnick BG, Fidell LS. Using Multivariate Statistics. Boston, MA: Allyn \& Bacon (2001).

44. Gelernter J, Kranzler H, Cubells JF. Serotonin transporter protein (SLC6A4) allele and haplotype frequencies and linkage disequilibria in African- and European-American and Japanese populations and in alcohol-dependent subjects. Hum Genet (1997) 101(2):243-6. doi:10.1007/s004390050624

45. Raine A. From genes to brain to antisocial behavior. Curr Dir Psychol Sci (2008) 17:323-8. doi:10.1111/j.1467-8721.2008.00599.x

46. Faraone SV, Perlis RH, Doyle AE, Smoller JW, Goralnick JJ, Holmgren MA, et al. Molecular genetics of attention-deficit/hyperactivity disorder. Biol Psychiatry (2005) 57(11):1313-23. doi:10.1016/j.biopsych.2004.11.024

47. Haddley K, Bubb VJ, Breen G, Parades-Esquivel UM, Quinn JP. Behavioural genetics of the serotonin transporter. Curr Top Behav Neurosci (2012) 12:503-35. doi:10.1007/7854_2011_186

48. Johnson BA, Ait-Daoud N, Seneviratne C, Roache JD, Javors MA, Wang XQ, et al. Pharmacogenetic approach at the serotonin transporter gene as a method of reducing the severity of alcohol drinking. Am J Psychiatry (2011) 168(3):265-75. doi:10.1176/appi.ajp.2010.10050755

49. Herman AI, Conner TS, Anton RF, Gelernter J, Kranzler HR, Covault J. Variation in the gene encoding the serotonin transporter is associated with a measure of sociopathy in alcoholics. Addict Biol (2011) 16(1):124-32. doi:10.1111/j.13691600.2009.00197.x

50. Glenn AL. The other allele: exploring the long allele of the serotonin transporter gene as a potential risk factor for psychopathy: a review of the parallels in findings. Neurosci Biobehav Rev (2011) 35(3):612-20. doi:10.1016/j.neubiorev.2010. 07.005

51. Henggeler SW, Pickrel SG, Brondino MJ. Multisystemic treatment of substanceabusing and dependent delinquents: outcomes, treatment fidelity, and transportability. Ment Health Serv Res (1999) 1(3):171-84. doi:10.1023/A: 1022373813261

52. Mitchell PB, Meiser B, Wilde A, Fullerton J, Donald J, Wilhelm K, et al. Predictive and diagnostic testing in psychiatry. Psychiatr Clin North Am (2010) 33:225-43. doi:10.1016/j.psc.2009.10.001

Conflict of Interest Statement: The authors declare that the research was conducted in the absence of any commercial or financial relationships that could be construed as a potential conflict of interest.

Received: 26 March 2014; accepted: 24 June 2014; published online: 07 July 2014. Citation: Chung T, Cornelius JR, Martin CS, Ferrell R, Maisto SA and Clark DB (2014) Serotonin transporter genotype linked to adolescent substance use treatment outcome through externalizing behavior. Front. Pediatr. 2:71. doi: 10.3389/fped.2014.00071

This article was submitted to Child Health and Human Development, a section of the journal Frontiers in Pediatrics.

Copyright (C) 2014 Chung, Cornelius, Martin, Ferrell, Maisto and Clark. This is an open-access article distributed under the terms of the Creative Commons Attribution License (CC BY). The use, distribution or reproduction in other forums is permitted, provided the original author(s) or licensor are credited and that the original publication in this journal is cited, in accordance with accepted academic practice. No use, distribution or reproduction is permitted which does not comply with these terms. 